\title{
Semejanzas entre el ajo (Allium sativum) costarricense y el ajo asiático según secuencias de ADN ribosomal
}

Karina Barboza Rojas'

Alejandro Hernández Soto²

Claudia Zúniga Vega ${ }^{3}$

Fecha de recepción: 15 de julio del 2011

Fecha de aceptación: 3 de noviembre del 2011

Barboza, K; Hernández, A; Zúñiga, C. Semejanzas

entre el ajo (Allium sativum) costarricense y el ajo asiático según secuencias de ADN ribosomal. Tecnología en Marcha.

Vol. 25, Nº 2. Abril-Junio 20 I 2. Pág 32-40.

Ingeniera en Biotecnología. Tecnológico de Costa Rica. Correo electrónico: karibarbosa 10@gmail.com

2 Profesor de la Escuela de Biología. Tecnológico de Costa Rica. Correo electrónico alejandro.hernandez.s@gmail.com

3 Catedrática, Escuela de Biología. Tecnológico de Costa Rica. Correo electrónico: czuniga@itcr.ac.cr 


\section{Resumen}

En Costa Rica, la producción de ajo (Allium sativum) es escasa y se limita principalmente a las regiones de Llano Grande de Cartago. Sin embargo, por el precio que tiene actualmente en el mercado, el ajo costarricense se vislumbra como una hortaliza que podría constituirse en un recurso valioso para los productores nacionales. Por lo anterior, en este artículo se presenta la caracterización mediante secuencias ribosomales de materiales de ajo provenientes Costa Rica y su comparación con ajo importado de China.

El ADN se extrajo a partir de hojas de vitroplantas de ajo mantenidas en un congelador a $-70^{\circ} \mathrm{C}$, pulverizadas en un mortero. El ADN ribosomal se amplificó, purificó y secuenció. Se realizó el análisis bioinformático de las secuencias ribosomales. El BLASTn permitió determinar que los productos de PCR amplificados corresponden a la secuencia parcial de los genes 28S y I8S (sitios de unión de los cebadores) y a la secuencia completa de la región ITS- I, 5.8S e ITS-2.

Se encontró que todas las secuencias alinearon en casi un 100\% con la accesión EU626375. I publicada en la base de datos del GeneBank, correspondiente al clon Allium sativum voucher BF-ALL-037. En general, las secuencias mostraron ser muy conservadas. Los puntajes obtenidos del alineamiento realizado con ClustalW reflejaron una identidad del 97 al 99\% entre las secuencias.

El presente estudio es el primer reporte de este tipo que se realiza sobre ajo costarricense y generó información básica e indispensable para continuar con los estudios moleculares de este cultivo.

\section{Palabras clave}

Allium sativum, ajo costarricense, ADNrn, regiones ITS.

\begin{abstract}
The garlic production (Allium sativum) in Costa Rica is scarce and is limited mainly to the region of Llano Grande in Cartago. However, because of its current price on the market, Costa Rican garlic could become a valuable resource for national producers. Therefore, this article presents the characterization by ribosomal sequences of garlic materials from Costa Rica and its comparison with imported garlic from China.
\end{abstract}

DNA was extracted from garlic vitroplant leaves maintained in a freezer at $-70^{\circ} \mathrm{C}$, pulverized in a mortar. Ribosomal DNA was amplified, purified and sequenced and the bioinformatic analysis of the ribosomal sequences was performed. The BLASTn revealed that the amplified PCR products correspond to the partial sequence of $28 \mathrm{~S}$ and $18 \mathrm{~S}$ genes (primers binding sites) and to the complete sequence of the ITS- I, 5.8S and ITS-2 region.

It was found that all sequences aligned in with almost a 100\% with the accession EU626375. I published in the GeneBank database, corresponding to A. sativum voucher BF- ALL- 037 clone. In general, sequences showed to be highly conserved. The scores of alignment with ClustalW reflected 97 to 99\% identity between the sequences.

This study is the first report of this kind conducted on Costa Rican garlic and generated basic and essential information for further molecular studies of this crop.

Key words

Allium sativum, Costa Rican garlic, nrDNA, ITS regions. 


\section{Introducción}

El ajo (Allium sativum) L. es una especie diploide del género Allium, familia Alliaceae, y del orden Asparagales; que se cultiva en todo el mundo y se utiliza como condimento y planta medicinal (García, 1994; Stavelíková, 2008).

El comercio internacional del ajo se caracteriza por presentar pocos países oferentes y una gran cantidad de países demandantes. De acuerdo con la FAO (2009), la producción mundial es de casi I 5 millones de toneladas y casi el 80\% (12 millones) proviene de la China. Desde 1970, la producción mundial ha aumentado más de cuatro veces mientras que el área de producción aumentó ligeramente menos de tres veces, por lo tanto, indica un incremento en el rendimiento (Campos, 200 I; Cavagnaro \& Galmarini, 2007).

En Costa Rica se cultiva mayoritariamente en la zona de Llano Grande de Cartago, entre mayo y agosto. La producción de ajo criollo no es suficiente para suplir la demanda nacional debido a la escasez de semilla (bulbos), la cual proviene de un pequeño porcentaje de las cosechas anteriores que se almacenan para futuras siembras. El sabor y aroma del ajo costarricense son algunas de las características de preferencia del consumidor nacional (García, 1994), pero presenta deficiencias en cuanto al número de bulbillos y diámetro del bulbo o cabeza. Lo anterior implica que la mayoría del producto que se consume es importado de China, principalmente por el tamaño y el precio.

El agricultor costarricense tiene el potencial de producir ajo de alta calidad, por lo que resulta esencial investigar el germoplasma que utiliza, el cual permitiría el futuro desarrollo de materiales genéticos con propiedades adecuadas de producción a nivel local, aprovechamiento de las cualidades organolépticas de las variedades nacionales y aumento de resistencia a enfermedades, para que pueda llegar a ser un producto competitivo, de alta calidad y productividad.

En suma, el establecimiento de un programa de mejoramiento de ajo tiene implícito disponer de información sobre la variabilidad genética del material de uso nacional, a fin de contar con un punto de partida para hacer un uso eficiente de los materiales autóctonos y los recursos implicados en esfuerzos dedicados al rescate de genotipos criollos y al mejoramiento genético. Uno de los métodos para caracterizar el material costarricense comprende el uso de técnicas de biología molecular.

En este país, no existen informes sobre estudios moleculares sobre este cultivo. El análisis de secuencias ribosomales, útiles para establecer relaciones filogenéticas, permitiría en principio contar con información de tipo molecular del ajo costarricense, siendo la base de futuros estudios moleculares. Lo cual facilitaría el desarrollo de protocolos estandarizados de extracción de ADN a partir de material in vitro, cebadores para la amplificación de estas secuencias de ajo criollo y optimización de este procedimiento por la técnica de la reacción en cadena de la polimerasa (PCR).

Además, se dispondría de las secuencias nucleotídicas de materiales de ajo mediante secuenciación, para diferentes análisis bioinformáticos. De esta forma se determinarían las similitudes del material costarricense con otros materiales publicados en las bases de datos existentes, lo que aportaría una información valiosa para el estudio molecular de este cultivo.

El ajo es un cultivo que mantiene un fenotipo diverso entre los diferentes clones, a pesar de ser exclusivamente reproducido asexualmente. La elaboración de mapas de diferentes miembros de familias de genes seleccionados ha permitido conocer más sobre su estructura molecular. Para ello se hace necesario caracterizar diferentes ejemplares y comparar sus secuencias para identificar polimorfismos en el ADN (por ejemplo, en regiones no codificantes) para utilizarlos como marcadores en poblaciones segregantes (Lee et al., 2003, Cavagnaro \& Galmarini, 2007; Al-Otayk et al., 2008).

La región ITS conformada por el gen del ARN ribosomal $5.8 \mathrm{~S}$ y los espaciadores transcritos internos (ITS-I e ITS-2) han sido utilizados con éxito para caracterizar filogenéticamente especies del género Allium (lpek et al. 2008). Estas regiones ITS son generalmente conservadas dentro de una especie pero muestran suficiente variación entre las especies y géneros para ser útil en la construcción de árboles filogenéticos (Brinegar, 2009).

Las bases de datos del Genebank hospedadas por el National Center for Biotechnology Information 
(NCBI) disponen de secuencias de ADN ribosomales de ajo (A. sativum), que son útiles para el adecuado uso y diseño de cebadores que permiten la caracterización molecular del material ajo criollo costarricense o de otras especies de interés agronómico. Actualmente se puede acceder a la bases de datos de The Barcode of Life Data Systems (BOLD, 20I0), en donde se encuentran publicadas secuencias de cebadores que amplifican diferentes ITS en plantas u otros organismos, útiles para estudios filogenéticos.

En este artículo se presenta la caracterización mediante secuencias ribosomales de materiales de ajo costarricense (A. sativum) provenientes de cuatro localidades.

\section{Materiales y métodos}

El presente trabajo se realizó en el Centro de Investigación en Biotecnología (CIB) del Tecnológico de Costa Rica, Cartago. Los materiales de ajo costarricense (A. sativum) fueron proporcionados por agricultores de las zonas de San Ramón de Alajuela, Miramar de Puntarenas, Santa Ana de San José, Llano Grande de Cartago y adicionalmente se trabajó con ajo importado de China.

\section{Material vegetal}

Se obtuvieron plantas in vitro de ajo (A. sativum) mediante la introducción en el laboratorio de ápices de bulbillos en un medio de cultivo compuesto por las sales M\&S (Murashige \& Skoog, 1962), suplementado con BAP, sacarosa $30 \mathrm{~g} / \mathrm{l}$, y Phytagel $^{\text {TM }}$ como gelificante. El pH se ajustó a 5,7.

Se diseccionaron los bulbos de ajo y a los bulbillos se les eliminó las capas superficiales que los rodean. Posteriormente se realizó un lavado con agua y jabón, y se llevó a cabo una desinfección con Agrymicin $®$ y Zetarán® 6 g/l por 45 minutos. Luego, en la cámara de transferencia de flujo laminar se realizaron tres lavados con agua destilada estéril. Seguidamente se aplicó un tratamiento con hipoclorito de sodio al $6 \%$ i.a durante 20 minutos. Para finalizar la desinfección se hicieron otros tres lavados con agua destilada estéril. Este protocolo es el que se utiliza en el CIB.

Bajo condiciones asépticas, se realizó la disección de los bulbillos y se extrajeron los ápices caulinares, los cuales se colocaron en el medio de cultivo y se mantuvieron durante un mes bajo luz difusa en un cuarto de crecimiento a una temperatura de $24^{\circ}$
C, 293 lux y un fotoperiodo de 16 horas, para la obtención de vitroplantas (figura I).

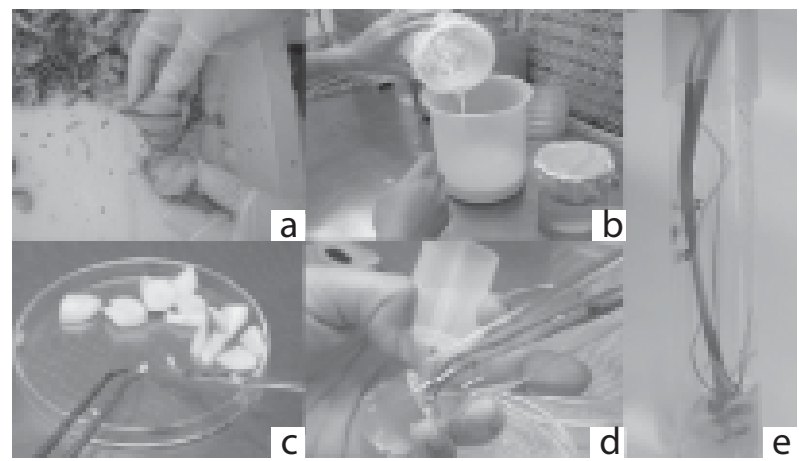

Figura I. Procedimiento para la obtención de vitroplantas de ajo (Allium sativum). a) Disgregación de los bulbos de ajo. b) Desinfección de los bulbillos. c) Extracción del ápice. d) Siembra del ápice en el medio de cultivo.

e) Vitroplanta de ajo.

\section{Extracción del ADN}

El ADN se extrajo a partir de hojas de vitroplantas de ajo mantenidas en un congelador a $-70^{\circ} \mathrm{C}$, pulverizadas en un mortero. Aproximadamente $5 \mathrm{~g}$ del polvo obtenido se transfirió a un tubo Eppendorfß y se realizó la extracción del ADN de acuerdo con el protocolo modificado del Wizard ( ) Genomic DNA Purification Kit). Posteriormente, los productos obtenidos se visualizaron mediante electroforesis en un gel de agarosa 1,5\% (p/v), en buffer de corrida TAE IX (40 mM Tris-acetato, pH 8.0 y I mM EDTA) a $70 \mathrm{~V}$ durante I hora, con GeneRulerTM I kb DNA ladder (Fermentas ${ }^{\circledR}$, Hanover, MD, USA) como marcador de peso molecular. El gel se tiñó con bromuro de etidio 0.5 $\mathrm{mg} / \mathrm{ml}$ (Sigmaß, St Louis, MO, USA) y se fotografió para evaluar la concentración y pureza del ADN.

\section{Cebadores}

Los cebadores sintetizados para la amplificación de la región del ADNrn I8S-ITSI-5,8S-ITS2-28S fueron tomados de Blattner (1999) y son: el ITSd-5'GGAAGGAGAAGTCGTAACAAGG-3' y el ITSr-5'CTTITCCTCCGCTTATTGATATG-3'.

\section{Amplificación del ADN ribosomal}

Para la amplificación de las secuencias del ADN ribosomal se utilizaron $5 \mu \mathrm{l}$ del ADN extraído, 2,5 $\mu$ l de cada cebador ( $100 \mathrm{ng} / \mu \mathrm{l})$ y $0,9 \mu \mathrm{l}$ de 
Taq Polimerasa (Dream Taq TM DNA Polymerase, Fermentas $5 \mathrm{u} / \mu \mathrm{l})$ por reacción de PCR. Las muestras se colocaron en un termociclador GeneAmp PCR System 9700 y Veriti (Applied Biosystems) para la amplificación de las muestras.

Para las secuencias ribosomales se utilizó el programa de termociclado que se describe en el cuadro 1.

Una vez que se obtuvieron los productos de PCR se tomaron $5 \mu$ de cada muestra amplificada y se mezclaron con $5 \mu$ l de buffer de carga $6 X$ (MassRuler $^{\text {TM }}$ DNA Ladder Mix, ready-to-use, Fermentas), los cuales se visualizaron mediante electroforesis en un gel de agarosa al 2\% (p/v), teñido con bromuro de etidio $0.5 \mathrm{mg} / \mathrm{ml}$ (Sigmaß, St Louis, MO, USA), en buffer de corrida TAE IX a 100 $\checkmark$ durante 40 minutos, con GeneRuler ${ }^{T M}$ I kb DNA ladder (Fermentas ${ }^{\circledR}$, Hanover, MD, USA) como marcador de peso molecular.

\section{Purificación de los productos de PCR}

Para la purificación de los productos de PCR amplificados se agregó un volumen de agua ultrapura estéril y un volumen de cloroformo a cada una de las muestras y se agitó suavemente mediante inversión de los tubos. Se centrifugó durante un minuto a I 4000 rpm, se tomó el sobrenadante y se colocó en un tubo limpio y estéril.

Posteriormente se adicionaron dos volúmenes de isopropanol y se mezcló suavemente por inversión, además se almacenó durante $20 \mathrm{~min}$ a $-70^{\circ} \mathrm{C}$ para precipitar el ADN. Transcurrido ese tiempo, se centrifugaron las muestras durante 5 minutos a 14000 rpm y se descartó el isopropanol. Finalmente, el ADN fue resuspendido en $30 \mu$ l de agua ultrapura estéril.
Secuenciación de los productos de PCR y análisis bioinformático de las secuencias ribosomales

Los productos amplificados fueron enviados a MacroGen USA para ser secuenciados en un analizador de ADN Applied Biosystems ABI 3730XL.

Las secuencias fueron editadas manualmente con base en las señales observadas en los electroferogramas en el programa BioEdit (Hall, 1999), y se realizó un BLASTn para determinar su similitud con las secuencias publicadas en el GeneBank.

Además, se realizó un alineamiento múltiple de las secuencias de las cinco localidades en estudio con la aplicación ClustalW (Higgins et al. 1994), para determinar la similitud entre las mismas.

Por otra parte, el análisis y creación de árboles filogenéticos se llevó a cabo utilizando el programa MEGA5 (Tamura et al. 2007), para ello previamente se realizó un alineamiento múltiple de las secuencias con la aplicación T-Coffee (Notredame et al. 2000). El estudio evolutivo se realizó utilizando tres métodos, el de mínima evolución propuesto por Rzhetsky \& Nei (1992), vecino más cercano (Saitou \& Nei, 1987) y UPGMA (Nei \& Kumar, 2000). Y se utilizó como grupo externo, la secuencia AJ4 I I944. I alojada en el GeneBank, correspondiente a la región del ADNr amplificado en cebolla (Allium cepa).

\section{Resultados}

\section{Material vegetal}

Tras un mes de cultivo in vitro, se obtuvieron vitroplantas de ajo de las zonas de Llano Grande, Miramar, Santa Ana, San Ramón y del ajo importado. El protocolo de introducción utilizado permitió obtener plantas libres de contaminación por hongos y bacterias. De esta manera, se contó con material limpio para la extracción del ADN genómico.

Cuadro I. Programa de termociclado utilizado para la amplificación de las secuencias ribosomales y del gen quitinasa de ajo (Allium sativum).

\begin{tabular}{|c|c|c|c|c|c|}
\hline & \multirow{2}{*}{$\begin{array}{c}\text { Desnaturalización } \\
\text { inicial del ADN }\end{array}$} & \multicolumn{3}{|c|}{30 Ciclos } & \multirow{2}{*}{ Extensión } \\
\cline { 3 - 5 } & & Desnaturalización & Tm & Extensión & \\
\hline Temperatura $\left({ }^{\circ} \mathrm{C}\right)$ & 95 & 95 & 56 & 70 & 70 \\
\hline Tiempo & $3 \mathrm{~min}$ & $30 \mathrm{seg}$. & $30 \mathrm{seg}$. & $45 \mathrm{seg}$. & $10 \mathrm{~min}$. \\
\hline
\end{tabular}




\section{Extracción de ADN}

El protocolo utilizado para la extracción del ADN genómico mediante el kit de extracción Wizard® Genomic DNA Purification Kit (Promega), resultó ser efectivo, ya que se obtuvo una sola banda de alto peso molecular (mayor a 7000 pb), libre de contaminación por ARN y proteínas.

\section{Amplificación de las secuencias ribosomales}

Los resultados de las pruebas de amplificación con los cebadores sintetizados para amplificar la región del ADN ribosomal nuclear I8S-ITSI-5,8S-ITS2$28 \mathrm{~S}$ de ajo (A. sativum), se muestran en la figura 2. Según se observa, para las 5 localidades estudiadas, se obtuvieron productos de PCR de similar peso molecular, aproximadamente $750 \mathrm{pb}$.

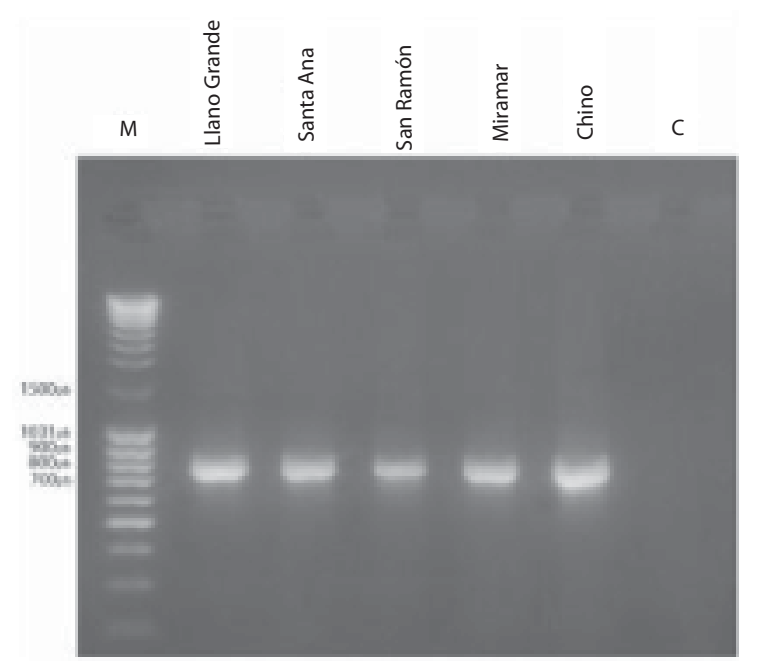

Figura 2. Gel de agarosa al I\% TAE IX que muestra la amplificación por PCR de la región I8S-ITSI-5,8SITS2-28S del ADN ribosomal nuclear de ajo (Allium sativum) a partir de material in vitro de las localidades de Llano Grande, Santa Ana, San Ramón, Miramar y un ajo importado de Asia. (M) marcador de peso molecular I kb Ladder, Fermentas ${ }^{\circledR}$, (C) Control negativo.

\section{Análisis bioinformático de}

las secuencias ribosomales

El BLASTn permitió determinar que los productos de PCR amplificados corresponden a la secuencia parcial de los genes 285 y 185 (sitios de unión de los cebadores) y a la secuencia completa de la región ITS-I, 5.8S e ITS-2. Así mismo, se encontró que todas las secuencias alinearon en casi un 100\% con la accesión EU626375. I publicada en la base de datos del GeneBank, correspondiente al clon Allium sativum voucher BF-ALL-037.

En general, las secuencias mostraron ser muy conservadas. Los puntajes obtenidos del alineamiento realizado con ClustalW reflejaron una identidad del 97 al 99\% entre las secuencias (cuadro 2).

Los árboles filogenéticos generados, coincidieron en agrupar todos los individuos en un solo grupo (figura 3). Los árboles se diseñaron a escala, con la longitud de las ramas en las mismas unidades que los de la distancia evolutiva utilizada para inferir el árbol filogenético (Nei \& Kumar, 2000).

\section{Discusión}

\section{Material vegetal}

Una forma de obtener ADN genómico de plantas de ajo (A. sativum) libre de agentes contaminantes, fue utilizando vitroplantas para hacer las extracciones. De esta manera, se evitó la posible extracción de ADN de microorganismos que pudieron estar en la superficie de las hojas y el pseudotallo de plantas provenientes directamente del campo y se contó con material de respaldo según la extracción de ADN realizada.

\section{Extracción del ADN}

El protocolo utilizado para la extracción del ADN genómico mediante el kit de extracción Wizard® Genomic DNA Purification Kit (Promega), resultó ser efectivo, ya que se obtuvo una sola banda de alto peso molecular (mayor a 7000 pb), libre de contaminación por ARN y proteínas (datos no mostrados). Este paso fue crítico para lograr la amplificación por PCR de los fragmentos de interés en esta investigación.

\section{ADN ribosomal y análisis filogenético}

En este estudio, el análisis filogenético realizado demostró que las distancias genéticas basadas en los ITS y el gen 5.8S del ARN ribosomal, son muy pequeñas, de tal manera que se dificulta la agrupación de los resultados. Los árboles filogenéticos que se generaron con distintos algoritmos y métodos (vecino más cercano, UPGMA y mínima evolución) 
Cuadro 2. Puntajes obtenidos del alineamiento múltiple realizado con el programa ClustalW entre las secuencias de ADNr de las cinco localidades en estudio.

\begin{tabular}{|c|c|c|c|c|}
\hline Secuencia A & Longitud $(\mathrm{nt})$ & Secuencia B & Longitud $(\mathrm{nt})$ & Identidad (\%) \\
\hline San_Ramón & 713 & Llano_Grande & 713 & 99.0 \\
\hline Llano_Grande & 713 & Chino & 713 & 99.0 \\
\hline Santa_Ana & 713 & San_Ramón & 713 & 98.0 \\
\hline Santa_Ana & 713 & Llano_Grande & 713 & 98.0 \\
\hline Santa_Ana & 713 & Chino & 713 & 98.0 \\
\hline San_Ramón & 713 & Chino & 713 & 98.0 \\
\hline Santa_Ana & 713 & Miramar & 713 & 97.0 \\
\hline San_Ramón & 713 & Miramar & 713 & 97.0 \\
\hline Miramar & 713 & Llano_Grande & 713 & 97.0 \\
\hline Miramar & 713 & Chino & 713 & 97.0 \\
\hline
\end{tabular}

concuerdan en agrupar todos los individuos en un solo grupo. Es decir, hay una cercanía filogenética elevada, de tal manera que es probable que el ajo costarricense tenga su origen en variedades asiáticas, demostrado con la alta similitud presentada con el ajo chino.

Sin embargo y debido a la poca información que se puede obtener de esta secuencia para el caso de ajo, es necesario estudiar otros genes que permitan caracterizar mejor los materiales costarricenses específicos.

Lo anterior concuerda con lo encontrado por Paredes et al. (2008), que indican que la escasa diversidad genética mostrada por el ajo contrasta con la alta variabilidad fenotípica observada en esta especie. En Costa Rica, algunos de estos factores que podrían incidir son las diferencias en las condiciones climáticas, especialmente en la temperatura; mutaciones, infección por virus (Guillén et al., 20 I I) y la composición del suelo donde se cultiva.

Es posible que la uniformidad genética observada en el ajo a nivel molecular, concuerde con lo esperado para una especie que se reproduce vegetativamente. En ausencia del proceso sexual en la propagación del ajo, las mutaciones al azar e inducidas han sido la única fuente de variabilidad genética en los programas de mejoramiento genético (Volk et al., 2004). Pero además, tratándose de la misma especie, era de esperarse que a nivel de ADN ribosomal, los resultados reflejaran una alta similitud en las secuencias, tomando en cuenta, que los genes del ARN ribosomal se caracterizan por ser altamente conservados entre las especies (Brinegar, 2009) y que su tasa de mutación con el tiempo es mínima debido al papel que tienen los ribosomas dentro de la maquinaria celular como encargados de la síntesis proteica.

\section{Conclusiones}

Las secuencias ribosomales no son informativas para diferenciar entre variedades de ajo debido a que mostraron ser altamente conservadas dentro de los materiales estudiados.

El presente estudio es el primer reporte de este tipo, que se realiza en el país sobre ajo costarricense y generó información básica e indispensable para continuar con los estudios moleculares de este cultivo en Costa Rica.

\section{Recomendaciones}

Debido a la uniformidad genética observada en el ajo (Allium sativum), se recomienda el diseño de cebadores y el estudio de otros genes que puedan presentar alguna variabilidad que permitan caracterizar los distintos materiales cultivados en Costa Rica. 


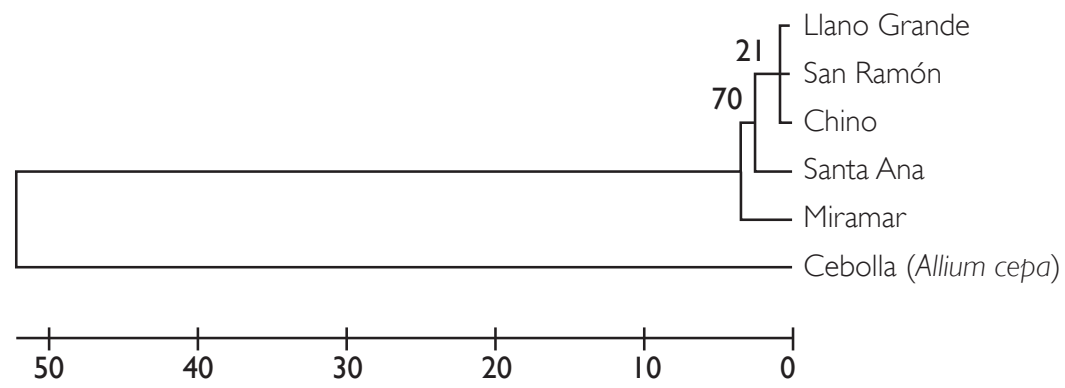

(a)

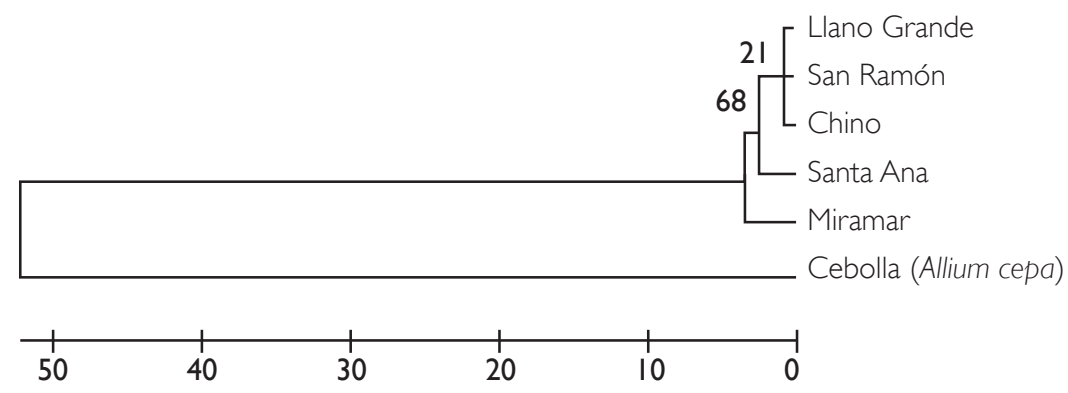

(b)

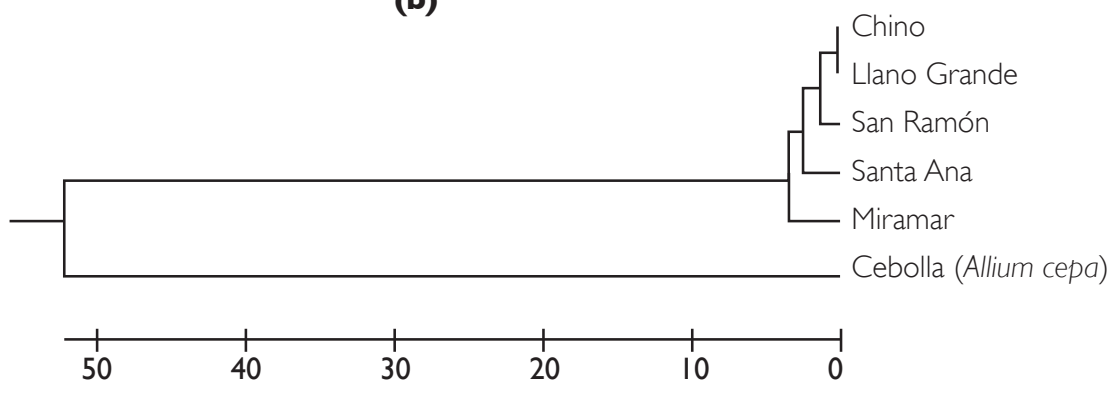

(c)

Figura 3. Árbol filogenético generado con las secuencias de la región ITSI-5.8S-ITS2 (a) por el método de mínima evolución; (b) el método del vecino más cercano; (c) método UPGMA. El porcentaje de réplicas de los árboles en los que los taxa asociados fueron agrupados (bootstrap: 1000 repeticiones) se muestran junto a las ramas.

\section{Bibliografía}

AL-Otayk, M.; El-Shinawy, M.; Motawei, M. (2008). Variation in productive characteristics and diversity assessment of garlic cultivars and lines using DNA markers. Env. \& Arid Land Agric. Sci. 20( I): 63-79.

Ayabe, M.; Sumi, S. (1998). Establishment of a novel culture method, stemdisc culture, and its practical application to micropropagation of garlic (Allium sativum L.). Plant Cell Reports. 17: 773-779.

Blattner, F. ( 1 999). Direct amplification of the entire ITS region from poorly preserved plant material using recombinant PCR. BioTechniques. 27: I | 80- I | 86.
Block, E. (1992). The organosulfur chemistry of the genus Allium - implications for organic sulfur chemistry. Angewandte Chemie, International Edition in English. 3।: | |35- I | 78.

Bold. 2010. The Barcode of Life Data Systems.

Brinegar, C. (2009). Assessing evolution and biodiversity in plants at the molecular level. Kathmandú University Journal of Science, Engineering and Technology. 5(2): |49-159.

Campos, A. (200I). Ajos: Antecedentes económicos de la producción mundial y nacional.Instituto de Investigaciones 
Agropecuarias, Ministerio de Agricultura, Chile Informativo La Platina. Obtenido desde http://alerce. inia.cl/docs/Informativos/In formativo I 3.pdf

Cavagnaro, P.; Galmarini, C.; Simon, P. (2005). Evaluación de caracteres ligados al sabory a características nutracéuticas de una colección de 162 clones de ajo. Resúmenes del XII Congreso Latinoamericano y XXVIII Congreso Argentino de Horticultura. Argentina.

Cavagnaro, P.; Galmarini, C. (2007). Garlic: Genome Mapping and Molecular Breeding in Plants. C. Kole (Ed.). Springer-Verlag Berlin Heidelberg. Germany.

Dellaporta, S.; Wood, J.; Hicks, J. (1983). A plant DNA minipreparation: version II. Planta Mol. Biol. Rep. I: 19-21.

FAO. (2009). Agriculture Production and Trade Statistics; Food and Agriculture Organization of the United Nations. Obtenido desde http://faostat.fao.org

García, M. (1994). Estudio de factibilidad económica de la producción de ajo (Allium sativum) en la zona de San Luis de Santo Domingo. Facultad de Agronomía Universidad de Costa Rica. Costa Rica.

Guillén, A. V.; Chacón, R.; Zúñiga, C. (20I I). Detección del virus del enanismo amarillo de la cebolla (OYDV) y el virus latente común del ajo (GCLV) en ajo (Allium sativum l) costarricense. (en prensa)

Hall, T. (1999). BioEdit: a user-friendly biological sequence alignment editor and analysis program for windows 95/98/NT. Nucleic Acids Symp. Ser. 4l: 95-98.

Higgins, D.; Thompson, J.; Gibson, T. (1994). Clustal W: improving the sensitivity of progressive multiple sequence alignment through sequence weighting, position-specific gap penalties and weight matrix choice. Nucleic Acids Res. 22: 4673-4680.

Ipek, M.; Ipek, A.; Simon, P. (2008). Genetic characterization of Allium tuncelianum: An endemic edible Allium species with garlic odor. Scientia Horticulturae. I I 5: 409-4I 5.

Katcher, H.; Schwartz, I. (1994). A distinctive property of Tth DNA polymerase: enzymatic amplification in the presence of phenol. BioTehniques. 16: 84-92.

Keusgen, M. (2002). Health and Alliums. En: Rabinowitch, H.; Currah, L. (eds). Allium Crop Science: Recent Advances. Wallingford, CAB International. UK.
Lee, H.; Eom, E.; Lim, Y.; Bang, J.; Lee, D. (2003). Construction of a garlic BAC library and chromosomal assignment of BAC clones using the FISH technique. Genome. 46: 5 I4520.

Molina, G.; Rosales, F. (2007). Diversidad de poblaciones de ajo (Allium sativum L.) cultivadas en Guatemala, definida por marcadores de ADN. Agronomía Mesoamericana. I8(1): 85-92.

Murashige, T.; Skoog, F. (1962). A revised medium for rapid growth and bioassays with tobacco tissue cultures. Physiol. Plant. 1 5: 473-497.

NCBI. (20 I0). National Center of Biotechnology. U.S.A.

NEI, M.; KUMAR, S. (2000). Molecular Evolution and Phylogenetics. Oxford University Press, New York.

Notredame, C.; Higginns, D.; Heringa, J. (2000). T-Coffee: A novel method for fast and accurate multiple sequence alignment. J. Mol. Biol. 302( I): 205- 17.

Olsen, G.; Woese, C. (1993). Ribosomal RNA: a key to phylogeny. The FASEB Journal. 7: I 13-123.

Paredes, M.; Becerra, V:; Gonzáles, M. (2008). Low Genetic Diversity Among Garlic (Allium sativum L.) accessions Detected using Random Amplified Polymorphic DNA (RAPD). Chilean Journal of Agricultural Research. 68(I): 3-12.

R.D.P. (20I0). Ribosomal Data Project. Obtenido desde http://www.cme.msu.edu/rdp/html /index.html

Rzhetsky, A.; Nei, M. (1992). A simple method for estimating and testing minimum evolution trees. Molecular Biology and Evolution. 9: 945-967.

Saitou, N.; Nei, M. (1987). The neighbor-joining method: A new method for reconstructing phylogenetic trees. Molecular Biology and Evolution. 4: 406-425.

Stavelíková, H. (2008). Morphological characteristics of garlic (Allium sativum L.) genetic resources collection. Information. Hort. Sci. (Prague). 35(3): I 30- 35.

Tamura, K.; Dudley, J.; Nei, M.; Kumar, S. (2007). MEGA4: Molecular Evolutionary Genetics Analysis (MEGA) software version 4.0. Molecular Biology and Evolution. 24:1596-1599.

Volk, G.; Henk, A.; Richards, C. (2004). Genetic diversity among U.S garlic clones as detected using AFLP methods. J. Amer. Soc. Hort. Sci. I29: 559-569. 